\title{
Correspondence
}

\section{Securing haemostasis during umbilical catheterisation in a neonate}

Sir,

The most common method of maintaining haemostasis after catheterisation of umbilical vessels is to secure the catheter to the edges of the cord by using a nylon stitch. When the cord is initially cut to insert the catheter there may be some blood loss, and furthermore some blood may ooze at times in spite of a stitch. We recommend tying firmly a single knot at the base of the cord using wet ribbon gauze $(15.2 \times 1.0 \mathrm{~cm})$. If this is done before the cord is cut, the catheters will pass without difficulty. Moreover should there be oozing from the cord the nursing staff have merely to tighten the knot before summoning medical help.

A. R. Gatrad and A. H. Gatrad Royal Manchester Children's Hospital, Pendlebury, Manchester M27 1HA

\section{Henoch-Schönlein purpura after chickenpox}

Sir,

Although Henoch-Schönlein purpura has been associated with many viruses, I have been unable to find a report of it after chickenpox.

An 8-year-old boy was admitted with a 36-hour history of abdominal pain, a tender right ankle joint, and a purpuric rash on his legs. 10 days earlier he had been unwell with a runny nose, sore throat, and cough, followed by a typical chickenpox rash, diagnosed by his family doctor.

On admission he complained of abdominal pain. He was apyrexial. There were a few submandibular nodes palpable and the tonsils were inflamed. Blood pressure was $110 / 70 \mathrm{mmHg}$. There were scattered lesions over his back and anterior chest wall showing crust formation consistent with chickenpox. Over the buttocks and extensor surfaces of the legs he had a macular-purpuric rash and small haemorrhagic lesions. His right ankle joint was tender and slightly swollen. The platelet count was normal. There was a trace of proteinuria on the first day only.

The history, together with the physical findings, was typical of Henoch-Schönlein purpura.

$\mathrm{He}$ made an uneventful recovery during the next 4 days and has remained well since.

C. J. Halle

Queen's Park Hospital, Haslingden Road, Blackburn BB2 $3 H H$

\section{Incidence of dental caries in coeliac children}

Sir,

As the result of comments made by parents at a Coeliac Society meeting to my paediatric colleague, $\mathrm{Dr} J$. Kuzemko, concerning the rate of decay of their children's teeth, I have reviewed the developing dentitions of 12 of the coeliac children under his care at Peterborough during the last 5 years, for tooth quality and incidence of dental caries.

Coeliac disease was diagnosed at ages ranging from 6 months to $13 \frac{1}{2}$ years, and the children have been on a gluten-free diet for between 3 and 11 years. This is a small sample, but the caries experience of this group of children was certainly no worse than one would expect in a similar group of normal local children. Only one case of gross caries of the deciduous dentition was found, and the parent confessed to plying the child with sweets to compensate for the restricted diet. Thus a gluten-free diet does not appear to affect the quality of the developing teeth as far as caries resistance is concerned.

What does have an effect is if the condition is not diagnosed correctly soon after its onset in the early months or years, as the severe constitutional disturbance causes hypoplasia of those areas of the crowns of the permanent teeth which are calcifying at that time. During the first year this affects the anterior teeth and first molars, and these hypoplastic areas are prone to decay and spoil the appearance of the teeth.

We should be interested to learn of the experience of others in this perhaps neglected area.

E. D. Fulstow Peterborough District Hospital, Thorpe Road, Peterborough PE3 6DA

\section{Atypical PKU with normal phenylalanine hydroxylase and dihydropteridine reductase activity in vitro}

Sir,

In a recent report (Archives, 1978, 53, 674) Schaub et al. described a patient with phenylketonuria who had normal hepatic activity of phenylalanine hydroxylase and dihydropteridine reductase. The patient responded to the administration of tetrahydrobiopterin (the natural cofactor of phenylalanine hydroxylase) by a rapid fall in plasma phenylalanine levels, and the authors postulate that their patient has a defect of biopterin synthesis.

Evidence for the existence of such a defect was obtained in two cases (those of Dr F. Rey in Paris and Dr K. Bartholomé in Heidelberg) who showed reduced serum 
and urine levels of total biopterin derivative (measured by Crithidia fasciculata assay) and an abnormal pattern of pterins on chromatography (Leeming et al., 1976). The results of the Crithidia assays carried out by one of us (R.J.L.) in 1975 on the patient of J. Bartholomé (Kaufman et al., 1975; Bartholomé et al., 1977) have not been published and we should like to present them (Table).

Table Levels of total biopterin derivative measured by Crithidia fasciculata assay in a patient with phenylketonuria (Bartholomé et al., 1977). Comparison with control values (mean $\pm S D$ )

\begin{tabular}{llll}
\hline Subjects & $\begin{array}{l}\text { Serum } \\
(\mu \mathrm{g} / \mathrm{l})\end{array}$ & $\begin{array}{l}\text { Urine } \\
(\mathrm{mg} / \mathrm{l})\end{array}$ & $\begin{array}{l}\text { Liver (ng/g } \\
\text { wet weight) }\end{array}$ \\
\hline Patient & $\begin{array}{l}0.2 \\
0.7\end{array}$ & 0.09 & 16.7 \\
$\begin{array}{l}\text { Adult liver stored } \\
\text { identically }\end{array}$ & - & - & 550 \\
$\begin{array}{l}\text { Children with 'classical' } \\
\text { PKU on diet }\end{array}$ & $\begin{array}{l}4.86 \pm 3.03 \\
1.78 \pm 0.79\end{array}$ & $2.46 \pm 1.76$ & - \\
$\begin{array}{l}\text { Normal children } \\
\text { Normal adults }\end{array}$ & $1.81 \pm 0.64$ & $2 \cdot 1 \pm 1.32$ & - \\
$\begin{array}{l}\text { Adults at abdominal } \\
\text { operation }\end{array}$ & - & - & $375 \pm 232$ \\
\hline
\end{tabular}

The levels of total biopterin activity in liver are markedly reduced, as are the levels in serum and urine. These results suggest that the patient, like that of Rey et al. (1977) and another reported recently by Kaufman et al. (1978), is deficient in biopterin. It remains to be explained why other measurements of hepatic cofactor activity failed to demonstrate an abnormality in Dr Bartholomé's case (Kaufman et al., 1975; Bartholomé et al., 1977).

Mr Leeming thanks Dr Bartholomé for allowing investigation of the patient.

\section{References}

Bartholomé, K., Byrd, D. J., Kaufman, S., and Milstien, S. (1977). Atypical phenylketonuria with normal phenylalanine hydroxylase and dihydropteridine reductase activity in vitro. Pediatrics, 59, 757-761.

Kaufman, S., Milstien, S., and Bartholomé, K. (1975). Letter: New forms of phenylketonuria. Lancet, 2, 708.

Kaufman, S., Berlow, S., Summer, G. K., Milstien, S., Schulman, J. D., Orloff, S., Spielberg, S., and Pueschel, S. (1978). New England Journal of Medicine, 299, 673-679.

Leeming, R. J., Blair, J. A., and Rey, F. (1976). Letter: Biopterin derivatives in atypical phenylketonuria. Lancet, 1, 99-100.

Rey, F., Harpey, J-P., Leeming, R-J., Blair, J-A., Aicardi, J., and Rey, J. (1977). Les hyperphenylalaninemies avec activité normale de la phenylalanine-hydroxylase: le deficit en tetrahydrobiopterine et le deficit en dihydropteridine reductase. Archives françaises de pédiatrie, 34, Supplement 2, 109-120.

R. J. LEEMING General Hospital, Steelhouse Lane, Birmingham $\mathrm{B} 46 \mathrm{NH}$ I. SMITH Institute of Child Health, 30 Guilford Street, London WC1N 1 EH
Dr Schaub and co-authors comment:

In our Short Report (Archives, 1978, 53, 674), it was not our intention to claim the first description of a defect of biopterin synthesis. We only wanted to show that tetrahydrobiopterin $\left(\mathrm{BH}_{4}\right)$ can be absorbed from the gut and can be applied to lower the blood phenylalanine level in atypical PKU due to a suspected defect of biopterin synthesis.

Nevertheless, in the meantime we have been able to localise the metabolic block in our patient (Niederwieser et al., 1979). Using high-voltage paper electrophoresis we found large amounts of neopterin in urine but no trace of biopterin or L-erythro-7, 8-dihydrobiopterin $\left(\mathrm{BH}_{2}\right)$. A comparable decrease of serum phenylalanine was observed after an oral administration of either $\mathrm{BH}_{4}, \mathrm{BH}_{2}$, or L-sepiapterin (Curtius et al., 1979). The last is postulated to be an intermediate in the biosynthesis (Eto et al., 1976; Gal et al., 1978) of $\mathrm{BH}_{2}$ from D-erythro7,8-dihydroneopterin triphosphate $\left(\mathrm{NH}_{2}-\mathrm{P}_{3}\right)$. Therefore, the metabolic block in this child must be between $\mathrm{NH}_{2}-\mathrm{P}_{3}$ and L-sepiapterin (Figure).

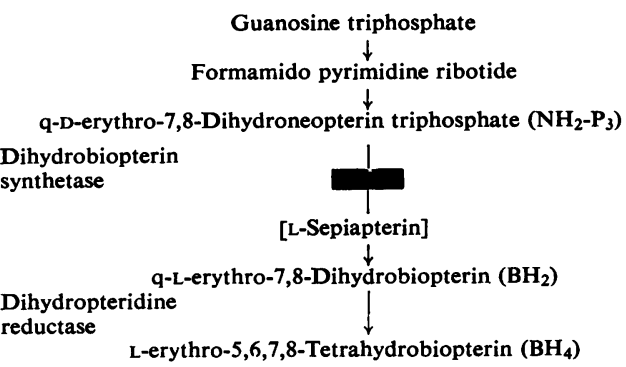

Figure Biopterin biosynthesis from guanosine triphosphate and location of the dihydrobiopterin synthetase defect.

\section{References}

Curtius, H. Ch., Niederwieser, A., Viscontini, M., Schircks, B., Otten, A., Schaub, J., Schiebenreiter, S., and Schmidt, H. (1979). Atypical phenylketonuria due to tetrahydrobiopterin deficiency. Diagnosis and treatment with tetrahydrobiopterin, dihydrobiopterin, and sepiapterin. Clinica chimica acta (in press).

Eto, I., Fukushima, K., and Shiota, T. (1976). Enzymatic synthesis of biopterin from D-erythro-dihydroneopterintriphosphate by extracts of kidneys from Syrian golden hamsters. Journal of Biological Chemistry, 251, 6505-6512.

Gal, E. M., Nelson, J. M., and Sherman, A. D. (1978). Biopterin. III. Purification and characterisation of enzymes involved in the cerebral synthesis of 7,8-dihydrobiopterin. Neurochemical Research, 3, 69-88.

Niederwieser, A., Curtius, H-Ch., Bettoni, O., Bieri J., Schircks, B., Viscontini, M., and Schaub, J. (1979). Atypical phenylketonuria caused by 7,8-dihydrobiopterin synthetase deficiency. Lancet, 1, 131-133.

JÜRGEN SCHAUB Children's Hospital, University of Munich, Lindwurmstrasse 4, D-8 München 2, Western Germany A. Niederwieser AND H. Ch. CuRTIUS Department of Pediatrics, University of Zurich, Switzerland 